\title{
New Year Resolution for Solicitors and GPS- Discuss with Clients and Patients the Benefits of Lasting Powers of Attorney for Health Welfare. Planning for Tomorrow so as to Live Today with Peace of Mind
}

ISSN: 2578-0093

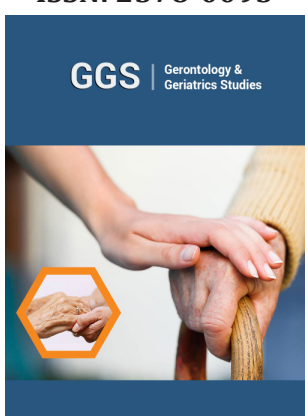

*Corresponding author: Richard F Department of Geriatrics, UK

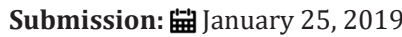

Published: 眥August 30, 2019

Volume 5 - Issue 1

How to cite this article: Richard F. New Year Resolution for Solicitors and GPSDiscuss with Clients and Patients the Benefits of Lasting Powers of Attorney for Health Welfare. Planning for Tomorrow so as to Live Today with Peace of Mind. Correlations and Treatments in the Literature. Gerontol \& Geriatric stud.5(1). GGS.000603.2019.

DOI: 10.31031/GGS.2019.05.000603

Copyright@ Richard F, This article is distributed under the terms of the Creative Commons Attribution 4.0 International License, which permits unrestricted use and redistribution provided that the original author and source are credited.

\author{
Richard F* \\ Department of Geriatrics, UK
}

\begin{abstract}
Abbreviations: LPAs: Lasting Powers of Attorney; LPEs: Later Life Planning Event
\end{abstract}

Introduction

The Mental Capacity Act 2005 introduced Lasting Powers of Attorney (LPAs) for Health \& Welfare (as well as Finance \& Property). The Medical and Legal Professions can help Patients/Clients achieve peace of mind by explaining to them the merits of making an LPA for Health \& Welfare. Solicitors acting for Private Clients in typical "High Street Practices" may be accustomed to a first meeting with a Client that goes as follows:

"Mr. Galvin, we have known for many years that it will be wise for us to make our Will. But it has taken us until now to come around to it and to come to see you". The Probate Registry tells us that as many as fifty-two percent of people still die without ever making a Will. [source: Lightspeed Research, July 2014]. Perhaps the delay and difficulty are explained at least in part by what is sometimes called 'the British attitude to death', and related matters, i.e. a reluctance to discuss such matters between ourselves and family. Perhaps this remains the best explanation for the fact that only a minority make Wills.

In practice, we have found that even fewer Clients have given any thought to the matter of who will make decisions if or when the day ever dawns that the Client is unable to make decisions for themselves. For a Solicitor, taking Instructions from a Client who has decided to make a Will, presents a perfect opportunity to discuss "what will happen between now and then?", i.e. if the Client become poorly and cannot make decisions before their death? Doctors, especially General Practitioners, can also assist their Patients to plan for Later Life by, likewise, discussing these matters with them. Once the subject of Planning for Later Life is raised, there are few Clients or Patients who do not agree with the wisdom of making a pair of LPAs: for Health \& Welfare as well as Finance \& Property. As a Client once put it here in the Office, "If I make an LPA for Finance \& Property, without making one for Health \& Welfare, is it not like insuring my car without insuring my house?" Happily, most Clients can readily think of at least two or more people who love and care for them and whom they can trust to make the right decisions if or when the time comes without ever being able to predict exactly what those decisions might be! It is common practice to ask the Client to appoint a minimum of two Attorneys together with one Replacement Attorney. There are three reasons for doing so. Firstly, serious problems will arise if a sole Attorney should die or become poorly before the Client has need of their assistance. Secondly, the task of being an Attorney will seem less daunting to those who have been asked to act, "a job shared is a job halved". Thirdly, with at least two Attorneys to make decisions, there is greater protection for the Attorneys themselves from those who might wish to cast aspersions. In addition, Clients 
will customarily be reminded to choose Attorneys who they know not only love and care for them but whom they can trust to work closely and happily with each other. As a High Street Firm in the Tame side area of Greater Manchester, over the past few years we have been very happy to assist people to consider such matters by way of hosting Later Life Planning Events. These take place in the Community in venues such as in local Churches. We have found that this enables people to consider planning for their Later Life in a secure and sympathetic setting. The Firm and our Clients have had the invaluable help of Dr Richard Fitton, a General Practitioner from Glossip.

At those Later Life Planning Events (LPEs) Dr Fitton's wisdom and learning has been helpful to people in understanding such contentious issues as the Liverpool Care Pathway and matters as to how decisions are made by the Medical Profession when caring for Patients/Clients coming to the end of their days. As a result, a significant number of those attending have gone on to make holistic plans for Later Life and Beyond. They have made a pair of LPAs and a Will in which, amongst other details, they have included Instructions for their Funeral Arrangements. They have understood that a Funeral may be of more importance to the bereaved than to the deceased! Dr Fitton has been of help in assisting the Firm to advise Clients and their families in any case which we, as Solicitors, may have a doubt as to whether the Client has the required level of understanding to be able to make a valid LPA. He has been responsible for drafting the following clause for inclusion in an LPA for Health \& Welfare in 'Part A, Section 7-Guidance to your Attorneys'.

That Guidance reads,

a) You may access all of my Personal, Medical and Social Care Records.

b) You may apply for access to and/or copies of my Health and Social Care Records after my death it if is for the benefit of the health and welfare of my descendants and nearest of kin and not of detriment to my reputation.

c) You may register me with an accredited (by the Care Quality Commission) Home Care Organization and create an online information sharing tool with them and my Attorneys to jointly manage my Health \& Social Welfare.

Inclusion of such Guidance within an LPA (Health \& Welfare) seems timely as Government and NHS is actively promoting the concept of a Patient having ready access to his or her full Medical Records. The inclusion of the above Guidance in the LPA (Health \& Welfare) both allows the Client/Patient and family members to have peace of mind knowing that if the need should ever arise, their Attorneys will have full access to their Medical and Care Records. As Dr Fitton put it, Access to a full GP Record allows the Patient or their family to follow the course, investigations, treatment and complications of care. The notes also include information about Out-Patient appointments and future plans for management. We believe that it is significant that in the past two years, we have worked with over 70 Clients to prepare for their Later Life by making LPAs for Health \& Welfare as well as for Finance \& Property. Without exception, such Clients have included Dr Fitton's suggested Guidance. The Office of the Public Guardian is drafting new Standard Forms for both types of LPA. We understand that no date has yet been fixed for the introduction of the proposed new Forms. The present Form of LPA (Health \& Welfare) wisely continues to include Part A, Section 5- about life sustaining treatment; and the requirements for a Client to actively consider the matter by choosing either Option A or B. Likewise, we believe that there is an overwhelming argument in favor of the inclusion of the above Guidance suggested by Dr Fitton within the revised Form of LPA for Health \& Welfare. This would ensure that the Client would then make his or her own decision as to whether such Guidance was to be included in their particular LPA (Health \& Welfare).

Inclusion of this potential Guidance within the next revised Form would ensure that potential benefits to the Client and their family would not be overlooked by default. It is the intention of $\mathrm{Dr}$ Fitton and us to propose to the Office of the Public Guardian that this Guidance should be included within the new Form. In advocating the inclusion of such Guidance, Dr Fitton tells us, "From 2015 all English General Practitioners will be expected to begin to make the GP Medical Record available on-line to the Patient. Maternity, child health and hospital medical records will also become available online to Patients and/or their Parents. As a General Practitioner, I deal with dependent, ill and dying Patients. Relatives of my Patients often wish to know what is happening to their relatives but cannot find out because of traditional practices of Medical Confidentiality or because Clinicians are too busy to tell them. It is possible to overcome this barrier if the Patient makes a legal power (LPA for Health \& Welfare) to access their records. Relatives of Patients often believe that they have an absolute right to make decisions about the care of their relatives.

This is not so; and the belief can cause difficulties for Professionals who are making decisions about the end of life care for Patients especially when relatives have conflicting opinions about what is the best thing to do for the patient. Health \& Welfare Lasting Powers of Attorney would make some decisions easier for Caring Staff, as well as for the Patient and family. A number of our Patients have donated copies of their records to their relatives in the belief that their notes may be of help to their descendants because of the family history that they contain. As the Human Genomic Program rolls out, this decision will become more significant. A wish for the records to be donated to an Attorney can easily be included in the LPA (Health \& Welfare)". In July this year, Pope Francis released his ten top tips for becoming a happier person for promoting peace of mind. They included:

a) Tip number 1- "To Live and let Live" or the equivalent expression in Rome

a. 'move forward and let others do the same'. 
b) Tip number 2- "Be giving of yourself to others" People need to be open and generous with each other.

c) Tip number 3- "Proceed calmly in life".

At the present and in the future, both the Legal and Medical
Professions can help greatly Clients and their families to apply these Top Tips for Happiness by encouraging our Clients and Patients that they consider these matters and in most cases to make plans for their own lives so as to promote peace of mind both for the Clients/Patients themselves, and their families. 